\title{
Utility of Perineural Steroids Post Radiofrequency Neurotomy
}

\section{TO THE EDITOR:}

We read with great interest the recent article by Singh et al (1) regarding the impact of local steroid administration on the incidence of neuritis following lumbar facet radiofrequency neurotomy (RFN). Our own practice at an academic teaching hospital is split with $25 \%$ of attendings giving steroids post radiofrequency neurotomy and $75 \%$ do not. This is personal preference with limited literature to support either decision. We applaud the authors for publishing on this interesting topic and starting to expand this evidence base.

As noted in their paper, this retrospective review was not able to distinguish between pain after RFN and postneurotomy neuritis. Pain experienced after RFN can be post-procedure pain, return to baseline pain state or neuritis. Without precise documentation, capturing these distinct pain complaints in a chart review is nearimpossible. It is not clear that assessing specifically for neuritis occurred at follow up visits.

The utility of steroids after RFN can be to prolong the duration of nerve blockade in an attempt to bridge the patients to the analgesic effect of the RFN and potentially prevent neuritis. The type of steroid and dose used may well affect the incidence of neuritis. The total steroid dose used must be divided between the multiple levels treated. An optimal effective dose has not been studied. It is unclear whether the particulate nature of the steroid would make a difference.

The level at which the RFN is performed is related to the incidence of neuritis. Steroid administration could potentially be more beneficial in the cervical spine where the incidence of neuritis post-RFN is higher
(2) compared to the sacral level (3). The duration and temperature of the ablation can create varying lesion sizes and in turn may affect pain or neuritis after the procedure.

Retrospective studies are subject to recall bias, and will miss patients who did not have follow up or failed to report their symptoms during this period. Several questions remain unanswered and as such, drawing firm conclusions to alter our practice is not possible. Well-designed randomized controlled clinical trials are warranted to further our understanding of this subject and enable us to make us evidence-based decisions.

\author{
Mark R. Williams, MD \\ Assistant Professor \\ Department of Anesthesiology \\ and Perioperative Medicine \\ University of Rochester School of Medicine \\ and Dentistry \\ 601 Elmwood Avenue, Box 604 \\ Rochester, NY 14642. \\ E-mail: mark1_williams@urmc.rochester.edu \\ Joseph Poli, MD \\ Assistant Professor \\ Department of Anesthesiology and \\ Perioperative Medicine \\ University of Rochester School of Medicine \\ and Dentistry \\ Rochester, New York
}

\section{REFERENCES}

1. Singh JR, Miccio VF Jr, Modi DJ, Sein MT The impact of local steroid administration on the incidence of neuritis following lumbar facet radiofrequency neurotomy. Pain Physician 2019; 22:69-74.
2.

Gazelka HM, Knievel S, Mauck WD, 3 Moeschler SM, Pingree MJ, Rho RH, Lamer TJ. Incidence of neuropathic pain after radiofrequency denervation of the third occipital nerve. J Pain Res 2014; 10:7:195-198.
Stolzenberg D, Gordin V, Vorobeychik Y. Incidence of neuropathic pain after cooled radiofrequency ablation of sacral lateral branch nerves. Pain Med 2014; 15:1857-186o. 